\title{
An assay for screening potential drug candidates for Alzheimer's disease that act as chaperones of the transthyretin and Amyloid- $\beta$ peptides interaction
}

Ellen Y. Cotrina, Ana Gimeno, Jordi Llop, Jesús Jiménez-Barbero, Jordi Quintana, Rafel Prohens, Isabel Cardoso, Gemma Arsequell ${ }^{\star}$

[a] Mrs. Ellen Y Cotrina and Dr. Gemma Arsequell, Institut de Química Avançada de Catalunya (I.Q.A.C.-C.S.I.C.), Jordi Girona 18-26, 08034 Barcelona, Spain. E-mail: gemma.arsequell@iqac.csic.es

Dr. Jordi Llop

CIC biomaGUNE, Basque Research and Technology Alliance (BRTA), 20014 San Sebastian, Spain

Dr. A. Gimeno and Prof. Dr. Jesús Jiménez-Barbero.

CIC bioGUNE, Basque Research and Technology Alliance (BRTA), Bizkaia Technology Park, Building 800, 48160 Derio, Spain. Ikerbasque, Basque Foundation for Science, Maria Diaz de Haro 13, 48009 Bilbao, Spain. Departament of Organic Chemistry II, Faculty of Science \& Technology, University of the Basque Country, 48940 Leioa, Bizkaia, Spain.

Dr. Jordi Quintana

Research Programme on Biomedical Informatics, Universitat Pompeu Fabra (UPF-IMIM), 08003 Barcelona, Spain.

Dr. Rafel Prohens

Unitat de Polimorfisme i Calorimetria, Centres Científics i Tecnologics, Universitat de Barcelona, Baldiri Reixac 10, 08028 Barcelona, Spain

Dr. Isabel Cardoso

i3S - Instituto de Investigação e Inovação em Saúde, Universidade do Porto, 4200-135 Porto, Portugal.

Supporting information for this article is given via a link at the end of the document

\begin{abstract}
The protein transthyretin (TTR) modulates Abeta (A $B$ ) peptides deposition and processing and this physiological effect is further enhanced by treatment with iododiflunisal (IDIF), a smallmolecule compound (SMC) with TTR tetramer stabilization properties that behaves as chaperone of the complex. This knowledge has prompted us to design and optimize a rapid and simple highthroughput assay that relies on the ability of test compounds to form ternary soluble complexes TTR/A $\beta / S M C$ that prevent $A \beta$ aggregation. The method uses the shorter $A \beta(12-28)$ sequence which is cheaper and simpler to use while retaining the aggregation properties of their parents $A \beta(1-40)$ and $A \beta(1-42)$. The test is carried out in 96-plate wells that are UV monitored for turbidity during $6 \mathrm{~h}$. Given its reproducibility, we propose that this test can be a powerful tool for efficient screening of SMCs that act as chaperones of the TTR/A $\beta$ interaction that may led to potential $A D$ therapies.
\end{abstract}

\section{Introduction}

Transthyretin (TTR) is a homotetrameric protein found in the plasma and cerebrospinal fluid (CSF) that transports thyroid hormones and retinol. ${ }^{[1]}$ It is most stable as a tetramer, but many point mutations are involved in pathological conditions caused by toxic TTR amyloid deposits in vital organs. ${ }^{[2]}$ It is relevant to note that TTR is the main Amyloid- $\beta(A \beta)$ binding protein in CSF. ${ }^{[3]}$ This binding is believed to naturally prevent $A \beta$ aggregation and toxicity in this fluid. This first physiological evidence suggesting a putative neuroprotective effect of TTR has been later confirmed by a number of biochemical and animal studies as well as comparative measures of TTR levels in healthy and AD patients. ${ }^{[4]}$ The molecular mechanisms of TTR neuroprotection have not been fully elucidated. Recent data suggests that TTR interferes with $A \beta$ by redirecting oligomeric nuclei into non-amyloid

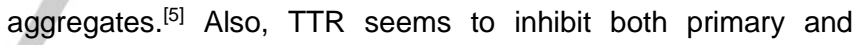
secondary nucleations of $A \beta$ peptides aggregation reducing the toxicity of their oligomers. ${ }^{[6]}$

In early in vitro studies we have gathered a first insight of the binding of TTR and $A \beta$ and on this binding enhancing role of a small set of TTR tetramer-stabilizing compounds. ${ }^{[7]}$ One of the compounds is an iodinated analogue of the nonsteroidal antiinflammatory drug (NSAID) diflunisal namely, iododiflunisal (IDIF) ${ }^{[8]}$ Later, we have shown that in vivo administration of IDIF to $A D$ transgenic mice, resulted in binding and stabilization of the TTR tetramer, decreasing brain $A \beta$ levels and deposition and improving the cognitive functions that are impaired in this AD-like neuropathology. ${ }^{[9]}$ By recent radiochemical studies, we have proved that preformed TTR-IDIF labelled complexes better penetrate the blood brain barrier (BBB) than free TTR and IDIF. ${ }^{[10]}$ By longitudinal in vivo molecular imaging study we have shown that oral treatment with IDIF in a transgenic mouse model of $A D$ delays hippocampal amyloid beta formation. ${ }^{[11]}$

To elucidate at the molecular level the mechanisms involved in these TTR/AB/IDIF interactions by biophysical methods we have used Saturation-Transfer Difference nuclear magnetic resonance (STD-NMR) techniques that have allowed us to identify the 17-mer peptide sequence $A \beta(12-28)$ as the main structural recognition motif. ${ }^{[12]}$ Interestingly, this short $A \beta$ amyloid peptide (VHHQKLVFFAEDVGSNK) has been extensively studied and is reported to exhibit essentially identical neurotoxic behavior 
and fibril formation features as the $A \beta(1-42)$ and (1-40) peptides and thus has been used as a short model of the full $A \beta$ peptides (Supporting information). ${ }^{[13]}$ Structural studies of this $A \beta(12-28)$ amyloid sequence have shown to contain a domain known as the "hydrophobic core" (residues 17-21) and a $\beta$-turn (residues 2228). ${ }^{[14]}$ These peptide stretches look essential for the formation of large aggregates and fibrils in the $A \beta(1-40)$ and $A \beta(1-42)$ longer peptides. ${ }^{[15]}$ Thus, mutations in the hydrophobic core such as Phe19/Pro19 have a large influence on the aggregation properties and even prevent fibrillization. ${ }^{[16]}$ Also, the aggregation characteristics of $A \beta(12-28)$ have a strong $\mathrm{pH}$ dependence. ${ }^{[17]}$ Interestingly, this same $A \beta(12-28)$ sequence has also been identified among the key determinants for the recognition of full $A \beta s$ by other amyloid binding proteins, such as ApoE ${ }^{[18]}$ and human serum albumin (HAS). ${ }^{[19]}$

Furthermore, in our biophysical studies of these ternary interactions we have also used isothermal titration calorimetry (ITC) techniques that have provided conclusive proof of stable complex formation in solution between these TTR, A $\beta$ and IDIF molecular species. Thus, both $A \beta(1-42)$ and $A \beta(12-28)$ do not bind with IDIF but form binary complexes with TTR. In turn, binary TTR/IDIF complexes bind more effectively than TTR alone with $A \beta$ species to form ternary complexes. This more effective binding provided by IDIF allow us to talk about a chaperoning effect of IDIF upon TTR/A $\beta$ binding. ${ }^{[20]}$

With this information at hand, we envisioned a simple ternary reaction system composed by TTR, A $\beta(12-28)$ and a SMC acting as chaperone that could be easily monitored for aggregates formation in a high throughput screening (HTS) format that could allow to screen for other chaperones. In such a system the chaperone could prevent aggregate formation through soluble ternary complex formation and the extent of precipitate formation could be an indirect measure of the chaperone potency. For setting such a system we have revisited our former turbidimetric method for screening of potential TTR fibrillogenesis inhibitors. Our method used a mutant TTR and was optimized as to carry kinetic monitoring of TTR aggregation by simply measuring the turbidity of 96-plate wells by UV. Turbidimetry kinetics were used to assess the potency of fibrillogenesis inhibition compounds. ${ }^{[21]}$ In this case, to design a simple and rapid assay, turbidity appeared again a good choice for reaction monitoring. Thus, given that native TTR is a thermostable protein that does not show amyloid properties in solution at neutral $\mathrm{pH}$, we aimed at measuring the ability of a particular test compound to prevent aggregation of the $A \beta(12-28)$ peptide in solutions also containing TTR. As here described, we have first optimized the operating conditions for $A \beta(12-28)$ aggregation by using common methods of rational Design of Experiments (DoE). ${ }^{[22]}$ Secondly, convenient $\mathrm{A} \beta(12-28) / T T R / S M C$ molar ratios as to discriminate the effect of different SMCs acting as TTR ligands were sought. The final assay setup comprises incubation of different test compounds with solutions containing both TTR and $A \beta(12-28)$ as to allow the formation of the ternary complexes in a 96-well format and the turbidimetry of the wells monitored for 6 hours by measuring the absorbance at $340 \mathrm{~nm}$. Turbidimetry is used as a measure of the chaperoning potency of the SMCs.

It is known that $A \beta$ peptides interact and form complexes with proteins other than TTR such as: Gelsolin, ${ }^{[23]}$ ApoJ (clusterin), ${ }^{[24]} \mathrm{ApoE}^{[25]}$ and HSA. ${ }^{[26]}$ These complexes also seem to interfere with $A \beta$ aggregation and therefore may constitute a new therapeutic target for AD. Owing the urgent need to feed the exhausted pipelines of drug candidates for AD (see more info in Supporting Information) we propose that the methodology here described, besides its potential for the discovery of TTR/A $\beta$ interaction modifying SMCs, may be inspiring to settle new screening methods for potential $A D$ therapeutic interventions based on other $A \beta$ interacting proteins.

\section{Results and Discussion}

Preliminary Experiments. Relative high quantities of the synthetic $A \beta(12-28)$ peptide and recombinant TTR were a requisite for this study. Thus, the $A \beta(12-28)$ amyloid peptide was in house synthesized at $\mathrm{mM}$ scale by microwave solid-phase peptide synthesis (SPPS) protocols. Preparation of recombinant TTR was achieved by expression in Escherichia coli following our previously described methods, with slight modifications to increase protein production. ${ }^{[21]}$ Yield of pure protein was $150 \mathrm{mg} / \mathrm{L}$ of culture and a batch of $500 \mathrm{mg}$ was produced (Supporting Information, Scheme S1). In a preliminary set of experiments the aggregation of separated $A \beta(12-28)$ and TTR solutions were compared with (2:1) molar mixtures of $A \beta(12-28)$ and TTR which were kept at $37^{\circ} \mathrm{C}$ under stirring in a neutral buffer and monitored at $340 \mathrm{~nm}$ for turbidity during $6 \mathrm{~h}$. It was observed that the peptide readily aggregates reaching a maximum in less than $3 \mathrm{~h}$, TTR solutions remained clean and (2:1) peptide/protein mixtures produced a faint precipitate. Also, additional mixtures of $A \beta(12$ 28) and TTR were challenged with IDIF. Thus, IDIF was incubated with TTR solutions at (1:2) molar ratios and then added to $A \beta$ peptide solutions at (2:1) peptide/protein ratios. No aggregates could be detected after 6 h (Supporting Information, Figure S3) and up to $18 \mathrm{~h}$ (Supporting Information, Figure S6). In addition, equimolar mixtures of $A \beta / I D I F$ and TTR/IDIF were prepared and monitored for turbidity to confirm that IDIF is not able to prevent $A \beta$ aggregation nor to induce TTR aggregation (Supporting Information, Figure S6).

Optimization of $\mathbf{A} \beta(12-28)$ aggregation. Having in mind that maximal sensitivity of aggregate detection by turbidimetry and minimal cost of reagents were particularly important factors, the HTS assay here described has been settled and optimized in two stages. In a first stage, the aggregation conditions of the $A \beta(12$ 28) peptide were selected and optimized. Thus, the following parameters: incubation temperature, nature and ionic strength of buffer solution, concentration of $A \beta(12-28)$ and selection of UV wavelength monitoring were either individually or collectively optimized by rational DoE methods. To identify the optimum wavelength that better differentiates between soluble and aggregated peptide we have performed spectral scannings (260$440 \mathrm{~nm}$ ) on $200 \mu \mathrm{M}$ solutions of $A \beta(12-28)$. One run was performed immediately after preparation of the solution and the second after standing at $37 \stackrel{\circ}{\circ}$ for $6 \mathrm{~h}$ (Supporting Information, Figure S4). The maximum absorption difference between the initial clean solution and the turbid final solution was observed at $340 \mathrm{~nm}$. This wavelength is in the $340-360 \mathrm{~nm}$ range, which has been used to characterize other amyloid aggregation processes and therefore was adopted as optimal for our study. ${ }^{[27]}$

For the optimization of the rest of the factors, this is, incubation temperature, ionic strength of buffer and concentration of peptide a factorial DoE was used. Reaction temperature and ionic strength were analyzed at two levels while concentration of 
reagents at three resulting in a $\left(3^{1} 2^{2}\right)$ factorial design (Supporting Information, Tables S1, S2 and S3). Accordingly, a total of 12 experiments that were repeated 3 more times with a sum of 48 runs. In addition, the block effect, this is, the influence of different batches of the peptide was also taken into account.

For each experiment, the mean value of the absorbance at $340 \mathrm{~nm}$ after 6 hours of reaction was taken as the variable response. The design and analysis of results were performed using the JMP software package (SAS Institute) ${ }^{[28]}$ while statistical significance was assessed by ANOVA (Supporting Information, Table S4). It was found that all the main factors (concentration, ionic strength, and temperature) and the interactions between concentration and the other two factors were statistically significant but not the temperature versus ionic strength interaction. As expected, the block factor was not statistically significant (Supporting Information, Table S5).

As seen from prediction profiles and desirability plots (Supporting Information, Figure S5) the most influential factor on absorbance was the peptide concentration. This can be seen from the examples of reaction profiles at different conditions provided in Figure 1. To reduce economic costs a concentration of $100 \mu \mathrm{M}$ of the peptide was selected for subsequent experiments. The other two factors were fixed at their low level (temperature at $37^{\circ} \mathrm{C}$ and low ionic strength (in the absence of $\mathrm{NaCl}$ salts, $0 \mu \mathrm{M}$ $\mathrm{NaCl})$.
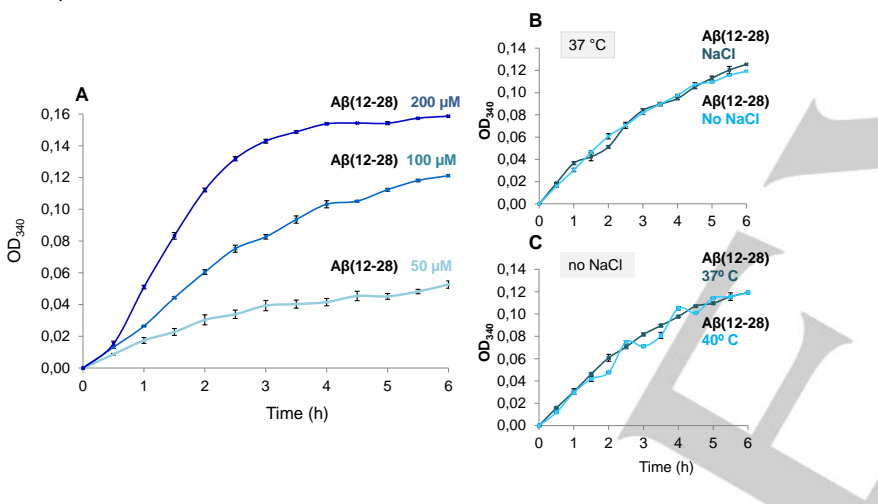

Figure 1. Aggregation kinetics of $A \beta(12-28)$ peptide at $37^{\circ} \mathrm{C}$ monitored by UV $(340 \mathrm{~nm}$ ) over $6 \mathrm{~h}$. A) At 50,100 and $200 \mu \mathrm{M}$ concentrations. B) In absence or presence of salts $([\mathrm{NaCl}]=100 \mathrm{mM})$. C) At different temperatures and absence of salts. Samples were assayed in duplicate and are representative of three ( $\mathrm{n}$ =6) $(A)$ or two different experiments $(n=4)(B$ and $C)$. Studies performed at $p H$ 7.4 in $25 \mathrm{mM}$ HEPES buffer, $10 \mathrm{mM}$ glycine and $5 \%$ DMSO (final concentration) at $37^{\circ} \mathrm{C}$.

Assay optimization. After setting the optimal $A \beta(12-28)$ aggregation conditions, in a second stage of the assay development, the most convenient peptide/protein ratio that may allow discrimination between different SMCs that act as TTR ligands was sought. Thus, in view of the preliminary experiments (Supporting Information, Figure S3) that used a (2:1) stoichiometric peptide/protein ratio, a discrete range of $A \beta(12-28)$ to TTR ratios going from an excess of peptide $(4: 1)$ to an excess of protein (1:2) were investigated (Figure 2A). Similar range of peptide/protein ratios were also studied in the presence of the TTR ligand IDIF (Figure 2B, 2C and 2D). From Figure 2B, it appears that the $(2: 1)$ peptide/protein ratio seems rather convenient for the quantification of the chaperoning effect of IDIF. In turn, this ratio also allows for a moderate consumption of protein. In addition, we have firm evidence from isothermal titration calorimetry (ITC) experiments that in these conditions, ternary $A \beta$ (12-28)/TTR/IDIF complexes are formed. ${ }^{20}$

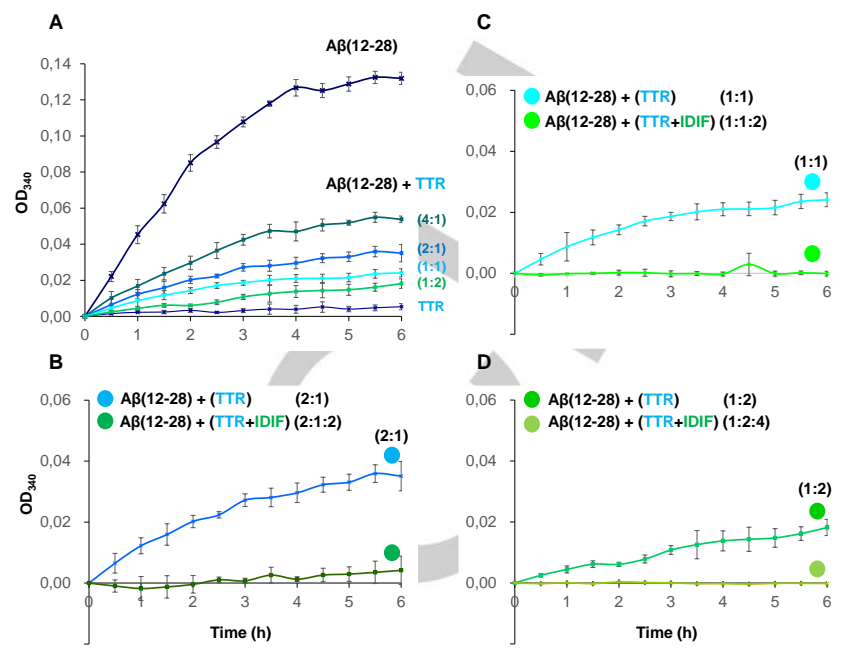

Figure 2. A) Kinetic profiles of the aggregation of $A \beta(12-28)$, TTR and $A \beta(12$ $28) /$ TTR mixtures at $(4: 1),(2: 1),(1: 1)$ and (1:2) molar ratios; $B) A \beta(12-28)$ aggregation course at $(2: 1) A \beta(12-28) /$ TTR molar ratio with or without IDIF (2 molar); C) $A \beta(12-28)$ aggregation course at (1:1) $A \beta(12-28) /$ TTR molar ratio with or without IDIF (2 molar); D) $A \beta(12-28)$ aggregation course at (1:2) $A \beta(12$ 28 )/ TTR molar ratio with or without IDIF (4 molar), measured by turbidity at $37^{\circ} \mathrm{C}$ over $6 \mathrm{~h}$. Samples were assayed in duplicate and are representative of two different experiments $(n=4)$. All of them performed at $\mathrm{pH} 7.4$ in $25 \mathrm{mM}$ HEPES buffer, $10 \mathrm{mM}$ glycine and 5\% DMSO (final concentration) at $37^{\circ} \mathrm{C}$.

HTS Assay Development. This information was next translated into a working HTS assay using 96-well microplates (Supporting Information, Scheme S2). In doing so, in each plate different positive and negative controls were always included. In particular, the $A \beta(1-11)$ sequence which does not show aggregation was taken as a negative control. It was always checked that TTR ligands alone do not modify the $A \beta(12-28)$ aggregation process.

The concentration of the test compounds in the assay was selected based on previous knowledge of their binding stoichiometry to the tetrameric form of TTR which is either (1:1) or (1:2) protein/ligand. A small quantity of DMSO $(5 \%$ final concentration) was always added to buffered stock solutions of ligands to improve their solubility. The protocol operation started with the incubation of the SMC $(100 \mu \mathrm{M})$ with the protein $(50 \mu \mathrm{M})$ for one hour at $37^{\circ} \mathrm{C}$ followed by addition of $A \beta(12-28)(100 \mu \mathrm{M})$ and then the plate was incubated for $6 \mathrm{~h}$ at $37^{\circ} \mathrm{C}$. 
Profiles of control experiments as well as results from a typical experiment using IDIF as a SMC ligand using optimal assay conditions are presented in Figure 3.
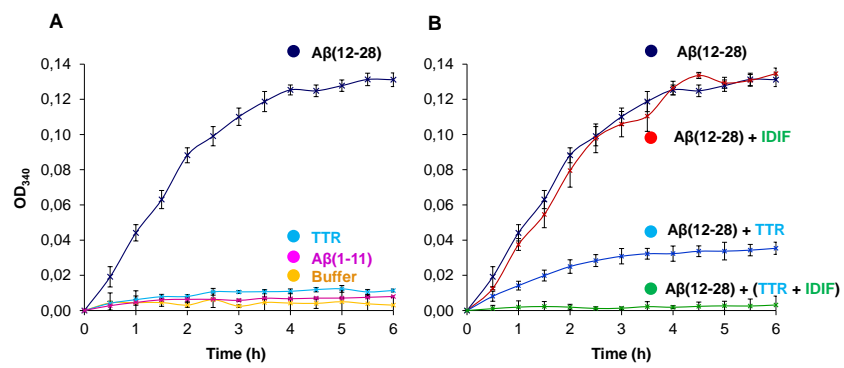

Figure 3. Aggregation kinetics of the $A \beta(12-28)$ peptide measured using the HTS operating format in a 96-well plates: A) Control experiments: dark blue, $A \beta(12-28)(100 \mu \mathrm{M})$; light blue, TTR $(50 \mu \mathrm{M})$; pink $A \beta(1-11)$ and yellow, buffer. $B)$ dark blue, $A \beta(12-28)$; red, $A \beta(12-28)$ with IDIF; light blue, $A \beta(12-28)$ with TTR (binary complex); green, $A \beta(12-28)$ plus TTR/IDIF mixture (ternary complex). Samples were assayed in duplicate and results are representative of three different experiments $(n=6)$. Studies were performed at $\mathrm{pH} 7.4$ in $25 \mathrm{mM} \mathrm{HEPES}$ buffer, $10 \mathrm{mM}$ glycine and 5\% DMSO (final concentration) at $37^{\circ} \mathrm{C}$.

Quantitative results are calculated from the UV absorbance of each well after 6 hours. The potency of a test compound is expressed as the percentage of reduction of the UV absorbance observed for the compound when compared to an $A \beta(12-28)$ aggregation control experiment. Thus, the potency of IDIF is $96 \%$ (Table 1).

Table 1. Quantification of SMCs potency.

\begin{tabular}{lccc}
\hline OD340 & p-value ${ }^{[a]}$ & $\begin{array}{c}\text { Reduction of } \\
\text { aggregation (\%) } \\
\text { (RA } \pm \text { SD \%) }\end{array}$ \\
\hline$A \beta(12-28)$ & $0.131 \pm 0.009$ & 0 \\
$A \beta(12-28)+$ TTR & $0.028 \pm 0.004$ & $0.000^{*}$ & $79 \pm 2.5$ \\
$A \beta(12-28)+[T T R+$ IDIF] & $0.006 \pm 0.005$ & $0.000^{*}$ & $96 \pm 1.4$ \\
\hline
\end{tabular}

[a] Statistically significant factors and interactions are those whose p-value < 0.05 ; $p$-value obtained using the non-parametric Wilcoxon rank-sum test. ${ }^{[29]}$

Analysis of the Z'-factor for the assay ${ }^{[30]}$ gave values of 0.9 for IDIF and of 0.87 for TTR meaning that the assay is well-suited for HTS.

Alternative assay monitoring. Following the assumption that $A \beta(12-28)$ aggregation yields amyloid structures, monitoring of the assay was also investigated using Thioflavin-T (ThT) fluorescence. Given that ThT tightly binds to amyloid structures, this method is widely accepted and used for the characterization of amyloid aggregates. ${ }^{[31]}$ As seen in Figure 4 the kinetic patterns of $A \beta(12-28)$ aggregation in the different conditions of the assay are consistent with the formation of amyloid structures which are greatly reduced by TTR/IDIF complexes. These patterns are in good accordance with the ones obtained by UV monitoring.

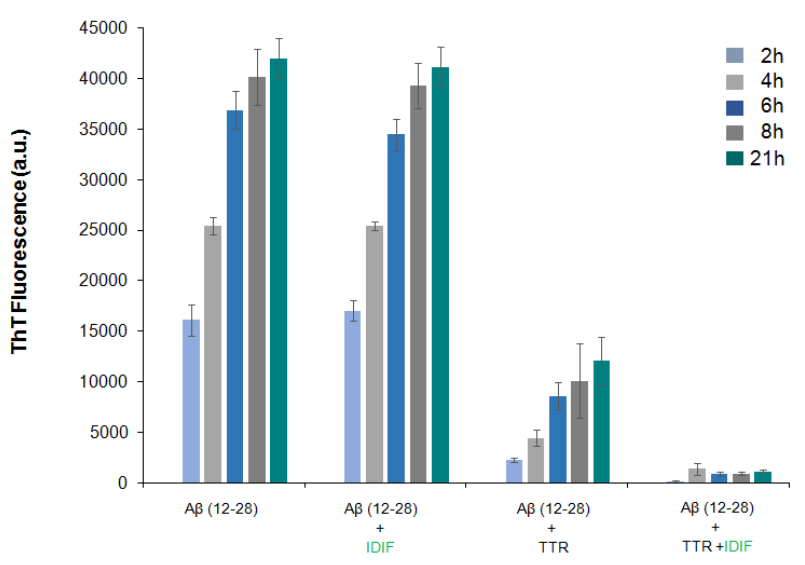

Figure 4. ThT fluorescence monitoring of the aggregation of $A \beta(12-28)$. Kinetic course of $A \beta(12-28)$ only; $A \beta(12-28)$ in the presence of IDIF; $A \beta(12-28)$ in complex with TTR and in complex with TTR stabilized with IDIF. ThT fluorescence was measured at $37^{\circ} \mathrm{C}$ at different time intervals. Studies were performed at $\mathrm{pH} 7.4$ in $25 \mathrm{mM}$ HEPES buffer, $10 \mathrm{mM}$ glycine and 5\% DMSO (final concentration) at $37^{\circ} \mathrm{C}$.

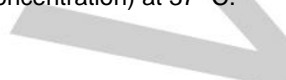

To further investigate the nature of the $A \beta(12-28)$ aggregates formed in the different assay conditions a morphological analysis by transmission electron microscopy (TEM) was performed. The ultrastructural examination revealed that after $48 \mathrm{~h}$ of incubation at $37^{\circ} \mathrm{C}, \mathrm{A} \beta(12-28)$ formed highly ordered and structured fibrils. However, in the presence of TTR/IDIF complexes only round and small particles were observed (Supporting Information, Figure S9).

It is well established that $A \beta$ peptides and its oligomeric forms are toxic to neural cells leading to apoptosis and cellular death. It is also settled that TTR protects against this neurotoxicity. $[5,6,32]$ Caspase- 3 activation is one of the methods to measure this toxicity. Using caspase-3 activation tests on the samples of our screening test we have observed that TTR can reduce up to $45 \%$ the levels of caspase- 3 activation while the TTR/IDIF complex effect is about $60 \%$ (Supporting Information, Figure S10).

Assay validation. To examine the proficiency of the assay to discriminate among structurally different SMC, a small set of TTR ligands was selected and tested (Figure 5). Two of them, tafamidis and diflunisal are licensed drugs. The $\mathrm{N}$-aryl anthranilic acids, $\mathrm{N}$-(3,5-dichlorophenyl)anthranilic acid (DCPA) and the $\mathrm{N}$ (3,5-difluorophenyl)anthranilic acid (DFPA) were chosen because of their good TTR binding properties. ${ }^{[7]}$ As seen in Figure 5D, 5E and $5 \mathrm{~F}$, among the four products, DCPA and DFPA show extensive chaperone properties similar to IDIF. Given that these three compounds are good TTR tetramer stabilizers, this condition seems a reasonable preliminary indication for the selection of potential chaperones entering the assay. Furthermore, ITC techniques has been used to corroborate the formation of the corresponding $A \beta(12-28) / T T R / S M C$ ternary complexes with the four selected compounds (Supporting Information, Figures S14 and S15). In addition, the aggregation kinetics of $A \beta(1-42)$ in the presence of the four selected SMC have been monitored by ThT assays giving coherent results with the turbidity measurements (Supporting Information, Figure S8). 


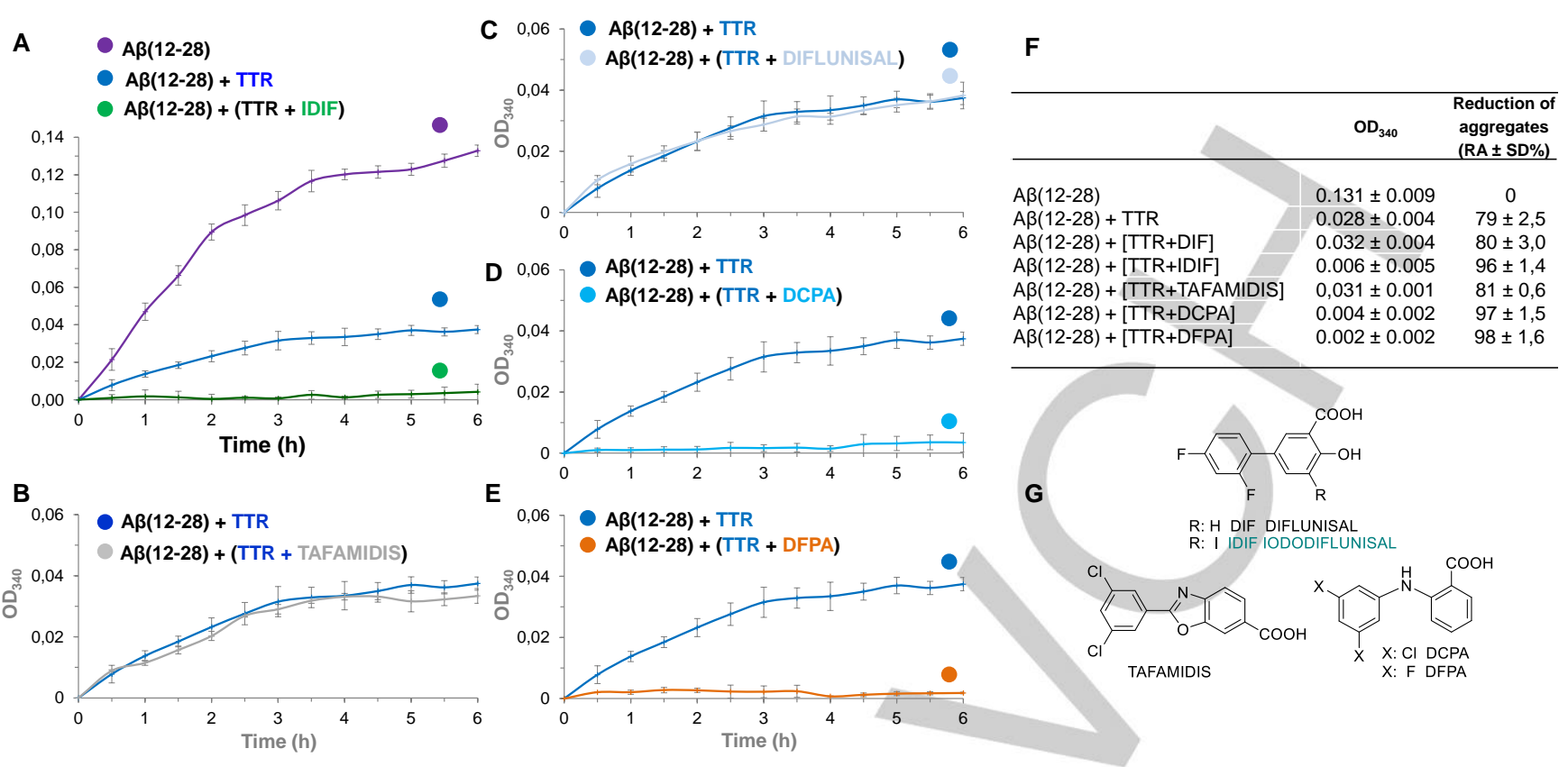

Figure 5. Aggregation kinetics of $A \beta(12-28)$ mediated by the four selected SMC as measured by the turbidity assay at $37^{\circ} \mathrm{C}$ over 6 h. Chaperoning effect of: $\left.A\right)$ IDIF, B) tafamidis, C) diflunisal, D) DCPA, and E) DFPA. Samples were assayed in duplicate and are representative of two different experiments ( $\mathrm{n}=4$ ). Studies were performed at pH 7.4 in 25 mM HEPES buffer, $10 \mathrm{mM}$ glycine and $5 \%$ DMSO (final concentration) at $37^{\circ} \mathrm{C}$. F) Parameters for aggregation from the turbidimetric assay. G) Chemical structures of the SMCs assayed.

\section{Conclusion}

In summary, we have designed and implemented a HTS assay to search for SMCs that may also be good chaperones of the TTR/A $\beta$ peptides interaction. The assay here described makes use of the more simple, easily handling and less costly $A \beta(12-28)$ peptide than the full-length $A \beta$ peptides. The assay monitors $A \beta(12-28)$ aggregation in the presence of both TTR and a SMC which is a TTR ligand that acts as chaperone of the $A \beta(12-$ 28)/TTR interaction. The aggregation kinetics can be monitored with parallel results by either the turbidity of the solutions as detected by UV or ThT fluorescence of the amyloid structures formed. The assay has been optimized for: 1) UV wavelength monitoring $(340 \mathrm{~nm}), 2) \quad A \beta(12-28)$ aggregation factors (concentration of peptide, buffer solution, incubation temperature) by using a factorial DoE of $\left(3^{1} 2^{2}\right)$, and 3) TTR/A $\beta(12-28)$ ratio as to minimize protein expenditure. The assay has been adapted to a 96-well plate format and tested using a set of 4 compounds that have different TTR binding properties. It was observed that TTR ligand ability correlates with chaperone efficiency of the $A \beta(12-$ 28)/TTR interaction. Chaperones always form ternary complexes $A \beta(12-28) / T T R / S M C$ as seen by ITC. We propose that this assay may be a simple and effective tool for screening chaperones of the $A \beta$ peptides/TTR interactions that may constitute potential $A D$ therapeutic agents. We also hope that the methodology here described may be inspiring to settle screening methods for chaperones acting on other proteins interacting with $A \beta$ peptides.

\section{Experimental Section}

Chemical compounds. Dimethyl sulfoxide (DMSO); $\mathrm{N}$-(2-hydroxyethyl) piperazine-N'-(2-ethanesulfonic acid) (HEPES); glycine;
Tris(hydroxymethyl)-aminomethane (Tris); TFA, Trifluoroacetic acid and dimethyl sulfoxide (DMSO) were acquired from Sigma Aldrich. The smallmolecule compound iododiflunisal (IDIF), an iodinated analogue of the NSAID diflunisal was synthesized in our lab IQAC-CSIC following our reported procedures [8]. The NSAIDs diflunisal (DIF) and $\mathrm{N}$-(3,5dichlorophenyl)anthranilic acid (DCPA) were from Sigma-Aldrich (diflunisal, D3281; DCPA, D8942; purity $\geq 98 \%$. The small-molecule $\mathrm{N}$-(3,5difluorophenyl)anthranilic acid (DFPA) was prepared in our lab as previously described. ${ }^{[7]}$ Purity of all final compounds was proved to be $\geq 95 \%$ by means of HPLC, HR-MS, and NMR techniques. Stocks of compounds assayed as small molecule ligands were dissolved in DMSO (ACS spectrophotometric grade, Sigma 154938) to a final $10 \mathrm{mM}$ concentration. Working solutions of ligands were prepared by taking an aliquot of $50 \mu$ of the DMSO $(5 \%)$ stock solution and diluting it with $950 \mu \mathrm{l}$ of buffer A ( $25 \mathrm{mM}$ HEPES buffer, $10 \mathrm{mM}$ glycine, $\mathrm{pH} 7.4$ was prepared in the absence of salt), ratio (1:20), equivalent to a $500 \mu \mathrm{M}$ concentration of ligand.

Amyloid peptides. The amyloid peptide sequences $A \beta(1-11)$ and $A \beta(12-$ 28) were purchased from Bachem AG (Switzerland) as trifluoroacetate salts (ref. $\mathrm{H}-2956$ and $\mathrm{H}-7910$, respectively. Purity by HPLC > 95\%). The $A \beta(12-28)$ peptide was also synthesized by Microwave Solid-Phase Peptide Synthesis (MW-SPPS) using Fmoc chemistry using the corresponding Fmoc protected amino acids. Cleavage from resin was performed using TFA/ $\mathrm{H}_{2} \mathrm{O} / \mathrm{TIS}(95: 2,5: 2,5)(\mathrm{V}: \mathrm{V}: \mathrm{V})$ and the peptide was precipitated with tert-butyl methyl ether. The peptide was purified by RPHPLC using a VersaFlash ${ }^{\circledR}$ system and characterized by analytical RPHPLC and UPLC-ToF MS and compared to the commercial sample acquired from Bachem (H-7910).

Recombinant wild-type human TTR (wt rhTTR) production and purification. Human wild type rhTTR gene was cloned into a pET expression system and transformed into E. coli BL21(DE3) Star. The phTTRwt-I/pET-38b(+) plasmid was provided by Prof. Antoni Planas (IQS, URL). The production of recombinant protein was performed at Erlenmeyer scale, protein production and purification were done as described previously following an optimized version of our protocol (Supporting Information Scheme S1) [21]. wt rhTTR was produced using a pET expression System. The expressed protein only contains an 
additional methionine on the $\mathrm{N}$-terminus if compared to the mature natural human protein sequence. wt rhTTR protein was expressed in E. coli BL21(DE3) cells harboring the corresponding plasmid. Expression cultures in $2 x Y T$ rich medium containing $100 \mu \mathrm{g} / \mathrm{mL}$ kanamycin were grown at $37^{\circ} \mathrm{C}$ to an optical density (at $600 \mathrm{~nm}$ ) of $4(\mathrm{OD} 600 \approx 4)$, then induced by addition of IPTG (1 mM final concentration), grown at $37^{\circ} \mathrm{C}$ for $20 \mathrm{~h}$, and harvested by centrifugation at $4{ }^{\circ} \mathrm{C}, 10000 \mathrm{rpm}$ for $10 \mathrm{~min}$ and resuspended in cell lysis buffer $(0,5 \mathrm{M}$ Tris- $\mathrm{HCl}, \mathrm{pH}$ 7.6). Cell disruption and lysis were performed by French press followed by a sonication step at $4{ }^{\circ} \mathrm{C}$. Cell debris were discarded after centrifugation at $4{ }^{\circ} \mathrm{C}, 11000 \mathrm{rpm}$ for $30 \mathrm{~min}$. Intracellular proteins were fractionated by ammonium sulfate precipitation in three steps. Each precipitation was followed by centrifugation at $12^{\circ} \mathrm{C}$, $12500 \mathrm{rpm}$ for $30 \mathrm{~min}$. The pellets were analyzed by SDS-PAGE (14\% acrylamide). The TTR-containing fractions were resuspended in $20 \mathrm{mM}$ Tris- $\mathrm{HCl}, 0.1 \mathrm{M} \mathrm{NaCl}, \mathrm{pH} 7.6$ (buffer A) and dialyzed against the same buffer. It was purified by lon exchange chromatography using a QSepharose High Performance (Amersham Biosciences) anion exchange column and eluting with a $\mathrm{NaCl}$ linear gradient using $0.1 \mathrm{M} \mathrm{NaCl}$ in $20 \mathrm{mM}$ Tris- $\mathrm{HCl} \mathrm{pH} 7.6$ buffer A to $0.5 \mathrm{M} \mathrm{NaCl} 20 \mathrm{mM}$ Tris- $\mathrm{HCl} \mathrm{pH} 7.6$ (buffer B). All TTR-enriched fractions were dialyzed against deionized water in three steps and were lyophilized. The protein was further purified by gel filtration chromatography using a Superdex 75 prep grade resin (GE Healthcare Bio-Sciences $\mathrm{AB}$ ) and eluting with $20 \mathrm{mM}$ Tris pH 7.6, $0.1 \mathrm{M} \mathrm{NaCl}$. Purest fractions were combined and dialyzed against deionized water and lyophilized. The purity of protein preparations was $>95 \%$ as judged by SDS-PAGE. Average production yields were $150-200 \mathrm{mg}$ of purified protein per liter of culture. Protein concentration was determined spectrophotometrically at $280 \mathrm{~nm}$ using calculated extinction coefficient value of $17780 \mathrm{M}^{-1} \mathrm{~cm}^{-1}$ for wtTTR. The protein was stored at $-20^{\circ} \mathrm{C}$.

Turbidity assay. In this assay the following stock solutions were used: Buffer A: $25 \mathrm{mM}$ HEPES buffer, $10 \mathrm{mM}$ glycine, $\mathrm{pH} 7.4$ was prepared in the absence of salt. Protein (TTR) stock: $9,5 \mathrm{mg} / \mathrm{mL}(170 \mu \mathrm{M})$ in $25 \mathrm{mM}$ HEPES buffer, $10 \mathrm{mM}$ glycine, $\mathrm{pH} 7.4$ and $5 \%$ DMSO (final concentration) was prepared in the absence of salt (buffer $\mathrm{A}$ ). For the $A \beta$ peptide stock: $0,4 \mathrm{mg} / \mathrm{mL}(200 \mu \mathrm{M})$ in $25 \mathrm{mM}$ HEPES buffer, $10 \mathrm{mM}$ glycine, $\mathrm{pH} 7.4$ and $5 \%$ DMSO (final concentration). For the small-molecule compound IDIF, a first solution of $3,76 \mathrm{mg} / \mathrm{mL}(10 \mathrm{mM})$ in DMSO was prepared. The final stock of the small-molecule IDIF was prepared by mixing $50 \mu \mathrm{L}$ of the previous DMSO solution with $950 \mu \mathrm{L}$ of buffer $\mathrm{A}$ (the final concentration of $5 \%$ DMSO).

First, the small-molecule compound and TTR complex was formed. To this end, $60 \mu \mathrm{L}$ of TTR stock was dispensed into the wells of a 96-well microplate. $40 \mu \mathrm{L}$ of small-molecule stock was added to give final concentrations of $100 \mu \mathrm{M}$. The plate was introduced in the microplate reader (SpectraMax M5 Multi-Mode Microplate Readers, Molecular Devices Corporation, California, USA) and incubated for $1 \mathrm{~h}$ at $37^{\circ} \mathrm{C}$ with orbital shaking $15 \mathrm{~s}$ every $30 \mathrm{~min}$. Then, $100 \mu \mathrm{L}$ of $\mathrm{A} \beta$ solution was added to the well to give a final concentration of $100 \mu \mathrm{M}$.

Other wells of the 96-well microplate are filled with: a) Buffer alone: $200 \mu \mathrm{L}$ of buffer A solution was added to the well; b) Negative control of $A \beta$ aggregation: $200 \mu \mathrm{L}$ of $A \beta(1-11)$ stock solution in buffer $A$ was dispensed into the wells; c) Testing TTR aggregation: $60 \mu \mathrm{L}$ of TTR stock were dispensed into the wells of a 96-well microplate and $140 \mu \mathrm{L}$ of buffer A were added; d) For the $A B(12-28)$ aggregation: $100 \mu \mathrm{L}$ of $A B(12-28)$ stock solution is dispensed into the wells and $100 \mu \mathrm{L}$ of buffer $A$ were added.

The plate was incubated at $37{ }^{\circ} \mathrm{C}$ in a thermostated microplate reader with orbital shaking $15 \mathrm{~s}$ every minute for $30 \mathrm{~min}$. The absorbance at $340 \mathrm{~nm}$ was monitored for $6 \mathrm{~h}$ at $30 \mathrm{~min}$ intervals. Data were collected and analyzed using Microsoft Excel software. All assays were done in duplicate.

$$
R A(\%)=\left[1-\left(\frac{A b s_{c}}{A b s_{\mathrm{A} \beta}+A b s_{c}}\right)\right] * 100
$$

The parameter monitored in this assay was used to calculate the percent reduction of formation of aggregates (RA \%) according to equation 1 , where $A b s_{A \beta}$ and $A b s_{c}$ are the final absorbance of the samples, in the absence or in the presence of the small-molecule compound/TTR complex; respectively.

Statistical analysis. The quality of an assay for HTS can be evaluated based on the Z'-factor ${ }^{[30]}$ which reflects the separation in mean values for the high and low controls while taking into consideration the variability within each group. A Z' factor below zero indicates poor quality assay with no separation between the high and low controls. A Z' factor value between 0.5 and 1 indicate an excellent quality assay with large separation between the high and low controls. Preferably, optimized assays have a Z' value above 0.5 . The statistical $Z$ '-factor can be calculated using equation 2 :

$$
Z^{\prime}=1-\frac{3 S D \text { of sample }+3 S D \text { of control }}{\mid \text { mean of sample }- \text { mean of control } \mid}
$$

where sample is the highest $R A \%$ for $A \beta(12-28)$ in presence of the binary complex (TTR+IDIF) or TTR alone, and the control is the $A \beta(12-28)$ aggregation. "Mean" is the mean value of the aggregation after $6 \mathrm{~h}$, and $\mathrm{SD}$ is the standard deviation.

Design of experiments (DoE). Factorial designs are one of the most important DoE because they produce efficient experiments that allow observation of responses to one factor at different levels of other factors in the same experiment. ${ }^{[22]} A$ factorial design of experiments was employed using the statistical software JMP 12.1.0 (SAS Institute). ${ }^{[28]}$ The variable to be maximized was the absorbance. Three factors were investigated: the concentration $(\mu \mathrm{M})$, the temperature $\left({ }^{\circ} \mathrm{C}\right)$ and the ionic strength $(\mathrm{mM}$ of $\mathrm{NaCl}$ ). Preliminary investigations were carried out to select initial analysis conditions, taking into account that temperature and ionic strength may have a nonlinear effect on the fibril formation, we have considered these two factors in a two-level design, the temperature at $37^{\circ} \mathrm{C}$ and $40{ }^{\circ} \mathrm{C}$ and the ionic strength $([\mathrm{NaCl}])$ at 0 and $100 \mathrm{mM}$. The concentration was considered at three levels 50,100 and $200 \mu \mathrm{M}$, to identify the sensitivity of our method. The UV absorption maxima for $A \beta$-peptide fibril formation is achieved at 340, 360 and $405 \mathrm{~nm}$. Specific experimental conditions tested, and the flow layout of a Design of Experiments can be found in the Supporting Information (Scheme S3).

Thioflavin-T fluorescence assays. The robustness of our turbidimetrybased method was further validated on the basis of comparative by Thioflavin-T (ThT) fluorescence assays on the same system. The ThT fluorescence was monitored at $37{ }^{\circ} \mathrm{C}$ using Gemini XPS plate reader (Molecular Devices) at an excitation wavelength of $440 \mathrm{~nm}$ and an emission wavelength of $490 \mathrm{~nm}$. Thioflavin- $\mathrm{T}$ (ThT) was dissolved in 25 $\mathrm{mM}$ HEPES buffer, $10 \mathrm{mM}$ glycine, $\mathrm{pH} 7.4$ and $5 \%$ DMSO to a final concentration of $25 \mu \mathrm{M}$. Aggregation of $A \beta(12-28) 50 \mu \mathrm{M}$ was performed in the presence of $25 \mu \mathrm{M}$ ThT. All solutions were dissolved in the same buffer. TTR was added to a final concentration of $25 \mu \mathrm{M}$. IDIF was added to a final concentration of $50 \mu \mathrm{M}$. For the ternary complex, TTR was incubated first with IDIF for $1 \mathrm{~h}$, then $A \beta(12-28)$ was added. The final volume was $200 \mu \mathrm{L}$ for all samples. Fluorescence intensity at $490 \mathrm{~nm}$ of each sample was monitored after each $2 \mathrm{~h}$ for $8 \mathrm{~h}$, and then at $21 \mathrm{~h}$. Measurements were performed as independent triplicates. Recorded values were averaged and background measurements (buffer containing $25 \mu \mathrm{M}$ ThT) were subtracted. Measurements were performed as independent triplicates. Recorded values were averaged and background measurements (buffer containing $25 \mu \mathrm{M}$ ThT) were subtracted.

Transmission Electron Microscopy (TEM). A $\beta(12-28)$ peptide $(100 \mu \mathrm{M})$, alone or with TTR $(20 \mu \mathrm{M})$ (alone or pre-incubated with IDIF for 1 hour at $37{ }^{\circ} \mathrm{C}$ ) was incubated at $37^{\circ} \mathrm{C}$ for $48 \mathrm{~h}$. For visualization by TEM, $5 \mu$ sample aliquots were absorbed to carbon-coated collodion film supported on 200-mesh copper grids, for 5 minutes, and negatively stained with $1 \%$ uranyl acetate. Grids were exhaustively examined with a JEOL JEM-1400 transmission electron microscope equipped with an Orious Sc1000 digital camera.

Cell culture and caspase-3 assay. SH-SY5Y cells (human neuroblastoma cell line; European Collection of Cell Cultures) were 
propagated in $25-\mathrm{cm}^{2}$ flasks and maintained at $37{ }^{\circ} \mathrm{C}$ in a $95 \%$ humidified atmosphere and $5 \% \mathrm{CO}_{2}$. Cells were grown in Dulbecco's minimal essential medium supplemented with $10 \%$ fetal bovine serum (Gibco $B R L$ ). Activation of caspase-3 was measured using the CaspACE fluorimetric 96-well plate assay system (Sigma), following the manufacturer's instructions. Briefly, $10 \mu \mathrm{M} A \beta(1-42)$ (Genscript) preincubated for $48 \mathrm{~h}$ at $4{ }^{\circ} \mathrm{C}$ with shaking, in $\mathrm{F} 12$ media (Gibco BRL) with or without $2 \mu \mathrm{M}$ TTR (alone or previously incubated with IDIF $(20 \mu \mathrm{M})$ for $1 \mathrm{~h}$ at $37^{\circ} \mathrm{C}$ ), were added to $80 \%$ confluent cells, cultured in 6-well plates, in Dulbecco's minimal essential medium with $1 \%$ fetal bovine serum, and further incubated for $24 \mathrm{~h}$, at $37{ }^{\circ} \mathrm{C}$. Subsequently, each well was trypsinized and the cell pellet was lysed in $100 \mu \mathrm{l}$ of hypotonic lysis buffer (Sigma). Forty $\mu \mathrm{L}$ of each cell lysate were used in duplicates for determination of caspase-3 activation. The remaining cell lysate was used to measure total cellular protein concentration with the Bio-Rad protein assay kit (Bio-Rad), using BSA as standard. Values shown are the mean of duplicates and the experiment was performed twice. Comparison between groups was made using the Student's t-test. A P value of less than 0.05 was considered statistically significant.

\section{Acknowledgements}

I. C. worked under the Investigator FCT Program which is financed by national funds through FCT and co-financed by ESF through HPOP, type 4.2 - Promotion of Scientific Employment and currently works under the Program CEEC_Institucional_2017. G. A. from IQAC-CSIC acknowledges a grant from Fundació Marató de TV3, Spain (Project ref. 20140330-31-32-33-34) and financial support from the Spanish Ministry of Economy (CTQ2016-76840-R). E.Y.C. acknowledges a contract from Ford-Fundación Apadrina la Ciencia. CIC bioGUNE acknowledges the European Research Council for financial support (ERC-2017-AdG, 788143-RECGLYC-ANMR), Instituto de Salud Carlos III of Spain, ISCIII (PRB3 IPT17/0019 to A. G.), Agencia Estatal Investigación of Spain, AEI (CTQ2015-64597-C2-1-P and RTI2018094751-B-C21) and the Severo Ochoa Excellence Accreditation (SEV-2016-0644). J.L. from CIC biomaGUNE acknowledges the Spanish Ministry of Economy and Competitiveness for financial support through grant CTQ2017-87637-R. G. A. from IQAC-CSIC acknowledges Dr. Maria José Bleda (CID-CSIC, Spain) for full support on statistical analysis, and Prof. Antoni Planas (IQS-URL) for full technical support on the TTR production; and Dr. David Amabilino for language editing and revision of this manuscript.

Keywords: high-throughput screening assay - small-molecule chaperones $\bullet$ transthyretin/A $\beta$ interaction $\cdot$ amyloid $\cdot$ Alzheimer's Disease $(A D)$ drug discovery

[1]. C. C. Blake, M. J. Geisow, S. J. Oatley, B. Rerat, C. Rerat, J. Mol. Biol. 1978, 121, 339-356.

[2] a) M. J. Saraiva, FEBS Lett. 2001, 498, 201-203; b) V. PlanteBordeneuve, J. Neurol. 2018, 265, 976-983.

[3] a) K. M. Pate, R. M. Murphy, Isr. J. Chem. 2017, 57, 602-612; b) P. Davidsson, A. Westman-Brinkmalm, C. L. Nilsson, M. Lindbjer, L. Paulson, N. Andreasen, M. Sjögren, K. Blennow, Neuroreport 2002, 13, 611-615.

[4] a) J. M. Serot, D. Christmann, T. Dubost, M. Couturier, J. Neurol. Neurosurg. Psychiatry 1997, 63, 506-550; b) C. A. Ribeiro; I. Santana, C. Oliveira, I. Baldeiras, J. Moreira, M. J. Saraiva, I. Cardoso, Curr Alzheimer Res. 2012, 9, 881-889; c) S. H. Han, E. S. Jung, J. H. Sohn, H. J. Hong, H. S. Hong, J. W. Kim, D. L. Na, M. Kim, H. Kim, H. J. Ha, Y H. Kim, N. Huh, M. W. Jung, I. Mook-Jung, J. Alzheimers Dis. 2011, 25 $77-84$.
[5] L. Nilsson, A. Pamrén, T. Islam, K. Brännström, S. A. Golchin; N. Pettersson, I. lakovleva, L. Sandblad, A. L. Gharibyan, A. Olofsson, J. Mol. Biol. 2018, 430, 2722-2733.

[6] S. A. Ghadami, S. Chia, F. S. Ruggeri, G. Meisl, F. Bemporad, J. Habchi, R. Cascella, C. M. Dobson, M. Vendruscolo, T. P. J. Knowles, F. Chiti Biomacromolecules 2020, 21, 1112-1125.

[7] C. A. Ribeiro, M. J. Saraiva, I. Cardoso, PloS ONE 2012, 7 (9):e45368.

[8] a) M. R. Almeida, B. Macedo, I. Cardoso, I. Alves, G. Valencia, G. Arsequell, A. Planas, M. J. Saraiva, Biochem. J. 2004, 381, 351-356; b) T. Mairal, J. Nieto, M. Pinto, M. R. Almeida, L. Gales, A. Ballesteros, J. Barluenga, J. J. Pérez, J. T. Vázquez, N. B. Centeno, M. J. Saraiva, A M. Damas, A. Planas, G. Arsequell, G. Valencia, G. PLoS One 2009, 4, e4124; c) L. Gales, S. Macedo-Ribeiro, G. Arsequell, G. Valencia, M. J. Saraiva, A. M. Damas, Biochem. J. 2005, 388, 615-662.

[9] C. A. Ribeiro, S. M. Oliveira, L. F. Guido, A. Magalhaes, G. Valencia, G. Arsequell, M. J. Saraiva, I. Cardoso, J. Alzheimers Dis. 2014, 39, 357370.

[10] X. Rios, V. Gómez-Vallejo, A. Martín, U. Cossío, M. Á. Morcillo, M. Alemi, I. Cardoso, J. Quintana, J. Jiménez-Barbero, E. Y. Cotrina, G. Valencia, G. Arsequell, J. Llop, Sci. Rep. 2019, 9(1) 13672.

[11] L. Rej, V. Gómez-Vallejo, X. Rios, U. Cossio, Z. Baz, E. Mujica, T. Gião, E.Y. Cotrina, J. Jiménez-Barbero, J. Quintana, G. Arsequell, I. Cardoso, J. Llop, J. Alzheimer's Dis. 2020 (accepted)

[12] A. Gimeno, L. M. Santos, M. Alemi, J. Rivas, D. Blasi, E. Y. Cotrina, J. Llop, G. Valencia, I. Cardoso, J. Quintana, G. Arsequell, J. JiménezBarbero, J. Med. Chem. 2017, 60, 5749-5758.

[13] a) P. E. Fraser, L. Lévesque, D. R. McLachlan J. Neurochem. 1994, 62 1227-1230; b) J. F. Flood, J. E. Morley, E. Roberts, Brain Res. 1994 663, 271-276; c) F. Hsu, G. Park, Z. Guo, ACS Omega 2018, 3, 8401 8407.

[14] a) S. Daly, A. Kulesza, F. Poussigue, A. L. Simon, C. M. Choi; G. Knight, F. Chirot, L. MacAleese, R. Antoine, P. Dugourd, Chem. Sci. 2015, 6, 5040-5047, Correction in: Chem Sci. 2016, 7, 1609-1610; b) J. Jarvet, P. Damberg, K. Bodell, L. E. G. Eriksson, A. Graslund, J. Am. Chem. Soc. 2000, 122, 4261-4268; c) J. Jarvet, P. Damberg, J. Danielsson, I. Johansson, L. E. Eriksson, A. Gräslund, FEBS Lett. 2003, 555, 371-374.

[15] a) T. A. Enache, A. M. Chiorcea-Paquim, A. M. Oliveira-Brett, Anal. Chem. 2018, 90, 2285-2292; b) R. Liu, C. McAllister, Y. Lyubchenko, M. R. Sierks, J. Neurosci. Res. 2004, 75, 162-171.

[16] S. J. Wood, R. Wetzel, J. D. Martin, M. R. Hurle, Biochemistry 1995, 34, 724-730.

[17] a) P. E. Fraser, J. T. Nguyen, W. K. Surewicz, D. A. Kirschner, Biophys. J. 1991, 60, 1190-1201; b) P. Mandal, N. Eremina, A. Barth, J. Phys. Chem. B. 2012, 116, 12389-12397.

[18] a) A. A. Golabek, M. Marques, M. Lalowski, T. Wisniewski, Neurosci. Lett. 1995, 191, 79-82; b) M. Sadowski, J. Pankiewicz, H. Scholtzova, J. A. Ripellino, Y. Li, S. D. Schmidt, P. M. Mathews, J. D. Fryer, D. M. Holtzman, E. M. Sigurdsson, T. Wisniewski, Am. J. Pathol. 2004, 165, 937-948.

[19] J. Milojevic, V. Esposito, R. Das, G. Melacini, J. Am. Chem. Soc. 2007 $129,4282-4290$

[20] E. Y. Cotrina, A. Gimeno, J. Llop, J. Jiménez-Barbero, J. Quintana, G. Valencia, I. Cardoso, R. Prohens, G. Arsequell, J. Med. Chem. 2020, 63 3205-3214.

[21] I. Dolado, J. Nieto, M. J. Saraiva, G. Arsequell, G. Valencia, A. Planas, J. Comb. Chem. 2005, 7, 246-252.

[22] a) R. O. Kuehl, Design of experiments: statistical principles of research design and analysis. $2^{\text {nd }}$ ed., Duxbury/Thomson Learning, Pacific Grove CA, 2000; b) G. E. P. Box, J. Stuart Hunter, J.; W.G. Hunter, Statistics for Experimenters: Design, Innovation, and Discovery. $2^{\text {nd }}$ ed., WileyInterscience, New Jersey, 2005.

[23] a) L. Ji, X. Zhao, Z. Hua, J. Alzheimers Dis. 2015, 44, 13-25; b) Y. Yu L. Zhang, C. Li, X. Sun, D. Tang, G. Shi, Angew. Chem. Int. Ed. Engl. 2014, 53, 12832-12835.

[24] a) A. R. Nelson, A. P. Sagare, B. V. Zlokovic, Proc. Natl. Acad. Sci. U. S. A. 2017, 114, 8681-8682; b) M. Beeg, M. Stravalaci, M. Romeo, A. D. Carrá, A. Cagnotto, A. Rossi, L. Diomede, M. Salmona, M. Gobbi, J. Biol. Chem. 2016, 291, 6958-6966.

[25] T. Wisniewski, E. Drummond, Neurobiol. Dis. 2020, 138, 104784 
[26] a) M. Boada, O. López, L. Núñez, Z. M. Szczepiorkowski, M. Torres, C Grifols, A. Páez, Alzheimers Dement. (N Y). 2019, 5, 61-69; b) M. Algamal, R. Ahmed, N. Jafari, B. Ahsan, J. Ortega, G. Melacini, J. Biol.Chem. 2017, 292, 17158-17168.

[27] a) C. Wurth, N. K. Guimard, M. H. Hecht, J. Mol. Biol. 2017, 319, 12791290; b) A. Roostaee, S. Côté, X. Roucou, J. Biol. Chem. 2009, 284 30907-30916; c) L. C. López, S. Dos-Reis, A. Espargaró, J. A. Carrodeguas, M. L. Maddelein, S. Ventura, J. Sancho, J. Med. Chem. 2012, 55, 9521-9530.

[28] JMP $®$, Version 12.1.0. SAS Institute Inc., Cary, NC, USA.

[29] F. Wilcoxon, Biometrics 1945, 1, 80-83.

[30] J. H. Zhang, T. D. Chung, K. R. A. Oldenburg, J. Biomol. Screen. 1999, 4, 67-73.

[31] H. LeVine 3rd., Protein Sci. 1993, 2, 404-410.

[32] R. Costa, A. Gonçalves, M. J. Saraiva, I. Cardoso, FEBS Lett. 2008, 582, 936-942. 


\section{Entry for the Table of Contents}

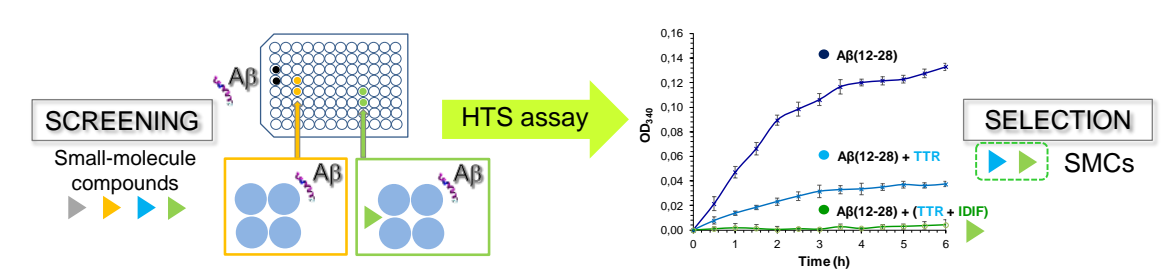

Potential drug candidates for Alzheimer's disease: a simple high throughput screening assay for chaperones of the Transthyretin and Amyloid- $\beta$ peptides interaction. 